Article

\title{
Arc Ablation Resistance and Dielectric Strength Properties of PTFE/BN Composites
}

\author{
Xianping Zhao ${ }^{1}$, Yongjie Nie ${ }^{1, *(\mathbb{D})}$, Tengfei Zhao ${ }^{1}$, Ke Wang ${ }^{1}$, Bingchen Song ${ }^{2}$, Shihu $\mathrm{Yu}^{3}$ and Shengtao $\mathrm{Li}^{2}$ \\ 1 Electric Power Research Institute, Yunnan power Gird Co., Ltd., Kunming 650217, China; \\ zhaoxianping01@im.yn.scg.cn (X.Z.); zhaotengfei@ncepu.edu.cn (T.Z.); wangke@dlyjy.yn.csg.cn (K.W.) \\ 2 State Key Laboratory of Electrical Insulation and Power Equipment, $X_{i}$ 'an Jiaotong University, \\ Xi'an 710049, China; sbc472241856@stu.xjtu.edu.cn (B.S.); sli@mail.xjtu.edu.cn (S.L.) \\ 3 Electric Power Research Institute of Guangdong Power Grid Corporation, Guangzhou 510080, China; \\ yushihu@dky.gd.csg.cn \\ * Correspondence: nieyongjie@stu.xjtu.edu.cn
}

Citation: Zhao, X.; Nie, Y.; Zhao, T.; Wang, K.; Song, B.; Yu, S.; Li, S. Arc Ablation Resistance and Dielectric Strength Properties of PTFE/BN Composites. Energies 2021, 14, 6705. https://doi.org/10.3390/en14206705

Academic Editor: Pawel Rozga

Received: 16 September 2021

Accepted: 11 October 2021

Published: 15 October 2021

Publisher's Note: MDPI stays neutral with regard to jurisdictional claims in published maps and institutional affiliations.

Copyright: (C) 2021 by the authors. Licensee MDPI, Basel, Switzerland. This article is an open access article distributed under the terms and conditions of the Creative Commons Attribution (CC BY) license (https:// creativecommons.org/licenses/by/ $4.0 /)$.

\begin{abstract}
The substantial improvements in transmission voltage, which have been adopted to meet fast-growing energy demands, require more reliable power equipment and higher-quality insulating materials. The polytetrafluoroethylene (PTFE) nozzle, as the key part of a high-voltage circuit breaker, is often subjected to arc ablation and breakdown phenomena. Thus, it is very urgent to develop nozzles with better performance. In this study, PTFE/boron nitride (BN) composites were prepared. The relationships among the $\mathrm{BN}$ filler loading, thermal transition properties, spectral reflectance properties, arc ablation resistance, and AC dielectric breakdown performances, as well as their corresponding mechanisms, were studied. Experimental results show that the thermal conductivity and thermal diffusivity of PTFE/BN composites increased monotonously with BN loading, and that both parameters were improved by $41 \%$ and $44 \%$, respectively, for $11 \mathrm{wt} \%$ composites compared with pure PTFE. Moreover, PTFE/BN composites had higher light reflectance in the wavelength range from 320 to $2500 \mathrm{~nm}$. The PTFE/BN composites presented better arc ablation resistance performance with increased $\mathrm{BN}$ loading, which was improved by $88.5 \%$. It is thought that the increased thermal conductivity, thermal diffusivity, the strong light reflectance, and surface sediment after arc ablation contribute to the improvement in arc ablation resistance performance. The AC breakdown strength of PTFE/BN composites was enhanced by $30.93 \%$, attributed to the good heat dissipation properties introduced by the BN fillers. Thus, filling BN into the PTFE matrix would be helpful to solve the equipment issue that comes from the improvement in transmission voltage.
\end{abstract}

Keywords: PTFE; BN; arc ablation; breakdown; thermal conductivity

\section{Introduction}

Ultra-high voltage (UHV) transmission technologies are widely used in power transmission all over the world due to their high transmission voltages and large transmission capacities [1,2]. In 2019, the world's first $\pm 1100 \mathrm{kV}$ DC transmission line from Zhundong to Wannan in China was put into operation, belonging to the highest voltage class and having the largest transmission capacity in the world [3]. However, the increased transmission voltage placed higher requirements on dielectric materials [4].

A nozzle is used to confine the electrical arc and guide the gas flow within circuit breakers, which are usually used for controlling circuit breaking in power systems [5]. Polytetrafluoroethylene (PTFE) is the raw insulating material used for processing nozzles due to its excellent insulation properties and machinability. However, the arc created during the switching-off process ablates and causes breakdown of the PTFE nozzle, seriously affecting the breaking performance of circuit breakers [6-10]. Therefore, it is essential to investigate the arc ablation and the breakdown properties of these nozzles and to develop better nozzle materials to solve or mitigate the above problems. In recent years, many studies on the 
arc model and establishing the dynamic properties of gases during the breaking process of the circuit breaker have been carried out [10-15], but few works have focused on the investigation of the ablation and breakdown properties of nozzles. Our previous work superficially studied the arc ablation resistance and breakdown properties of nozzle materials by filling BN of different sizes into PTFE $[16,17]$. It was found that arc ablation resistance is positively related with the thermal conductivity of the composites. Thus, enhancement in the thermal transport performance of nozzle materials may improve arc ablation resistance performance. The thermal transport performance of polymers can be enhanced by the following two ways: optimizing the structures of the polymers themselves or by filling their matrices with high-thermal-conductivity fillers (the filled polymers) [18-25]. Compared with the former methods, the latter methods have attracted much attention because the polymeric composites are easily achieved. For the polymeric composites, many fillers with high thermal conductivity, such as metal powder [18], metal oxide [19], metal or non-metal nitrides [20-23], and graphene [24,25], can be used to enhance thermal transport performance. Therefore, it is essential to select appropriate fillers according to the actual demand. It was reported that the thermal conductivity of hexagonal boron nitride $(h-\mathrm{BN})$ is up to $280 \mathrm{~W} /(\mathrm{m} \cdot \mathrm{K})[23]$ and is a good choice to improve the thermal transport performance of polymeric composites.

In this study, PTFE filled with various h-BN loadings was prepared to investigate the arc ablation and $\mathrm{AC}$ breakdown properties; the surface morphology before and after arc ablation, thermal transport, and spectral reflectance properties of PTFE/BN specimens were tested to investigate the corresponding mechanisms.

\section{Experimental Section}

\subsection{Preparation of PTFE/BN Specimens}

PTFE with a size of about $25 \mu \mathrm{m}$, supplied by Japan Daikin Corporation, and h-BN sheets with an average size of $5 \mu \mathrm{m}$, supplied by Beijing Deke Daojin Science and Technology Co., Ltd., were used for the preparation of PTFE/BN composites. A certain weight ratio of PTFE and $h$-BN powder were placed into a high-speed mixer and then mixed at a speed of $1000 \mathrm{rpm}$ for $1 \mathrm{~h}$. Then, the mixture was preprocessed into a cylindrical shape with a diameter of $80 \mathrm{~mm}$ and a height of $100 \mathrm{~mm}$ through the isostatic pressing method, with a pressure of $15 \mathrm{MPa}$ for $30 \mathrm{~min}$. The pressure was then released, and the prefabricated cylinder was placed into a sintering furnace for sintering. Several sintering procedures as shown in Figure 1 were carried out, separately. The prefabricated product was, firstly, heated from room temperature to $320^{\circ} \mathrm{C}$ with a heating rate of $5{ }^{\circ} \mathrm{C} / \mathrm{min}$, and then this temperature $\left(320^{\circ} \mathrm{C}\right.$ ) was maintained for $30 \mathrm{~min}$. After that, the temperature was increased from 320 to $340{ }^{\circ} \mathrm{C}$ with a heating rate of $2{ }^{\circ} \mathrm{C} / \mathrm{min}$, and then maintained at $340{ }^{\circ} \mathrm{C}$ for $30 \mathrm{~min}$. Then, the temperature was increased to $370^{\circ} \mathrm{C}$ in $30 \mathrm{~min}$ and maintained for $3 \mathrm{~h}$ before being naturally cooled to room temperature. Finally, six types of specimens with BN filler loading of 0, 3, $5,7,9$, and $11 \mathrm{wt} \%$ were prepared, and the corresponding specimens were named PTFE, PTFE-BN-3, PTFE-BN-5, PTFE-BN-7, PTFE-BN-9, and PTFE-BN-11, respectively. 


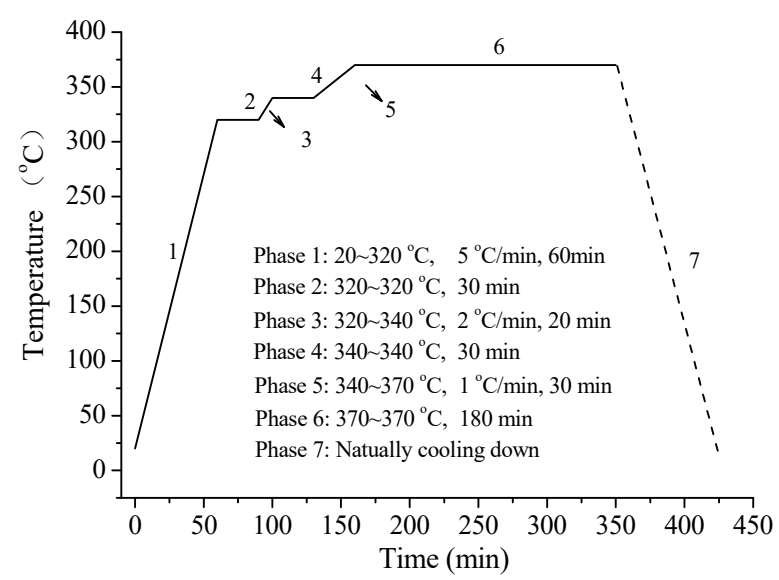

Figure 1. Sintering process of PTFE and PTFE/BN specimens.

\subsection{Characterization of PTFE/BN Composites}

A scanning electron microscope (SEM) of JSM-6930 was used to observe the dispersion of BN sheets in PTFE matrix, as well as the surface morphology of specimens after ablation. To observe the dispersion of BN sheets in PTFE, the fracture surface was obtained by breaking off the specimen in liquid nitrogen, which was then surface-sprayed with a layer of gold. For surface morphology observation of the arc ablation regions, the selected region was directly coated with a gold layer. After that, the SEM specimens were prepared.

LFA447 Nanoflash equipment was used to measure the thermal transport properties of specimens, including their thermal conductivity and thermal diffusivity. Firstly, the specimens were processed into a square with a thickness of $2 \mathrm{~mm}$ and a side length of $10 \mathrm{~mm}$ and dried in an oven at $60{ }^{\circ} \mathrm{C}$ for $5 \mathrm{~h}$. Then, the dried specimens were surfacesprayed with graphite powder. After that, the prepared specimens could be used for testing. In this study, the testing temperature was started at $50{ }^{\circ} \mathrm{C}$ and ended at $275{ }^{\circ} \mathrm{C}$, with a temperature interval of $25^{\circ} \mathrm{C}$. In this study, each specimen was tested 3 times, and the average value was used to characterize the thermal transport performances.

The spectral reflectance of PTFE/BN composites was tested by UV-Vis spectroscopy. The related research indicated that the wavelength of the arc ranges from $30 \mathrm{~nm}$ to $1.8 \mu \mathrm{m}$ [26]. However, the equipment cannot test the spectral properties when the wavelength is below $200 \mathrm{~nm}$. Thus, during testing, the wavelength ranged from 200 to $2500 \mathrm{~nm}$, including the ultraviolet region, the visible light region, and the infrared region.

Arc ablation resistance performance was measured based on IEC 61621. The testing equipment and the testing program were the same as in [16]. Specimens were placed between two-finger tungsten electrodes with a gap of $6.35 \mathrm{~mm}$, and the created arc ablated the specimens. The arc ablation resistance performance of the specimens was characterized by the amount of ablation, which is calculated by the weight difference before and after the arc ablation test. In this study, each specimen was tested 5 times, and the average arc ablation amount was defined as the arc ablation resistance performance.

The AC dielectric breakdown strength was measured with HJC-100 kV breakdown equipment according to ASTM D 149 standard, the same as in Ref. [17]. The tested specimens, with $0.5 \mathrm{~mm}$ thickness, were sandwiched between two spherical electrodes with a diameter of $25 \mathrm{~mm}$ and were put into the insulating oil at room temperature. During the tests, the voltage applied to the specimens was increased at a rate of $5 \mathrm{kV} / \mathrm{s}$ until breakdown occurred, and the breakdown voltage was recorded. Finally, the breakdown strength was obtained by the ratio of breakdown voltage to the specimen's thickness. In this study, the breakdown of each sample was tested 10 times, and the average breakdown strength was used for characterizing the dielectric strength of the specimens. 


\section{Experimental Results \\ 3.1. SEM Characterization}

Figure 2 shows the SEM images of PTFE/BN specimens with various BN loadings. From Figure $2 b-f$, it can be seen that the shape of $B N$ is a sheet, with a size of about $5 \mu \mathrm{m}$. In addition, the SEM images show that the BN sheets are distributed very uniformly in the PTFE matrix, and almost no agglomeration phenomenon were observed in the PTFE/BN composites. It seems that the distances between the $\mathrm{BN}$ sheets decrease gradually with increased BN filler loading. For instance, BN sheets are isolated within the PTFE with low $B N$ loading, as shown in Figure $2 b$. Whereas in Figure $2 d-f$, the $B N$ sheets are close to one other with the increase in filler loadings.
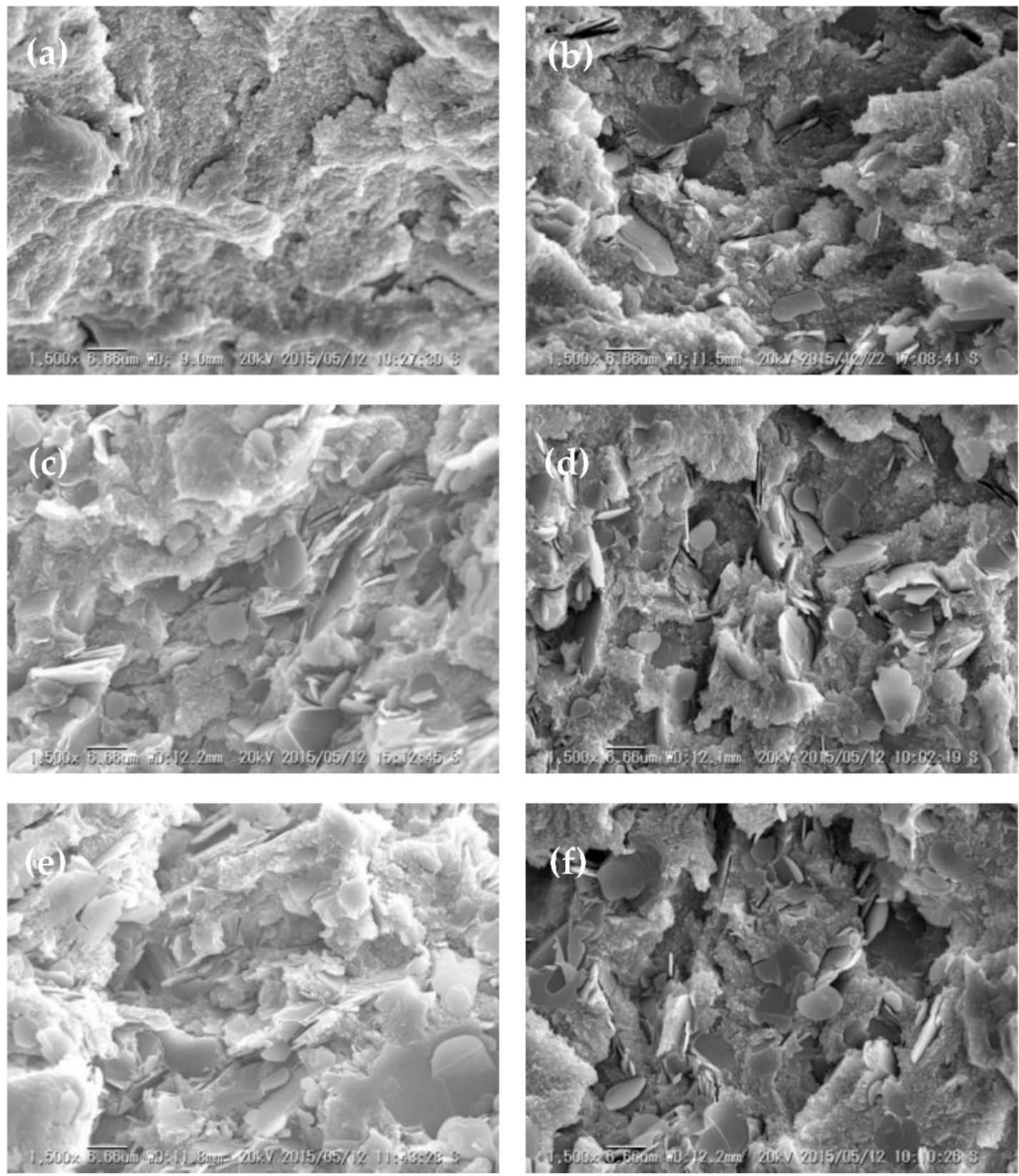

Figure 2. SEM images of (a) PTFE, (b) PTFE-BN-3, (c) PTFE-BN-5, (d) PTFE-BN-7, (e) PTFE-BN-9, and (f) PTFE-BN-11. 


\subsection{Thermal Transport Properties}

The thermal transport performances of the PTFE/BN composites were characterized by thermal conductivity, and the results can be seen in Figure 3. It is obvious that the thermal conductivity increases with increased BN loading at every temperature point, and that all of the PTFE/BN composites present higher thermal transport performance than pure PTFE. The PTFE-BN-11 specimen shows the best thermal conductivity of $0.481 \mathrm{~W} /(\mathrm{m} \cdot \mathrm{K})$, which improved by $41 \%$ compared with that of unfilled PTFE $(0.341 \mathrm{~W} /(\mathrm{m} \cdot \mathrm{K}))$ at $50{ }^{\circ} \mathrm{C}$. Thermal conductivity is defined as the amount of heat transferred per unit of time by a unit of temperature gradient (temperature reduction of $1 \mathrm{~K}$ over a length of $1 \mathrm{~m}$ ) through a unit of heat transfer surface. Thus, the improvement in thermal conductivity means more heat energy can be transferred in the same condition.

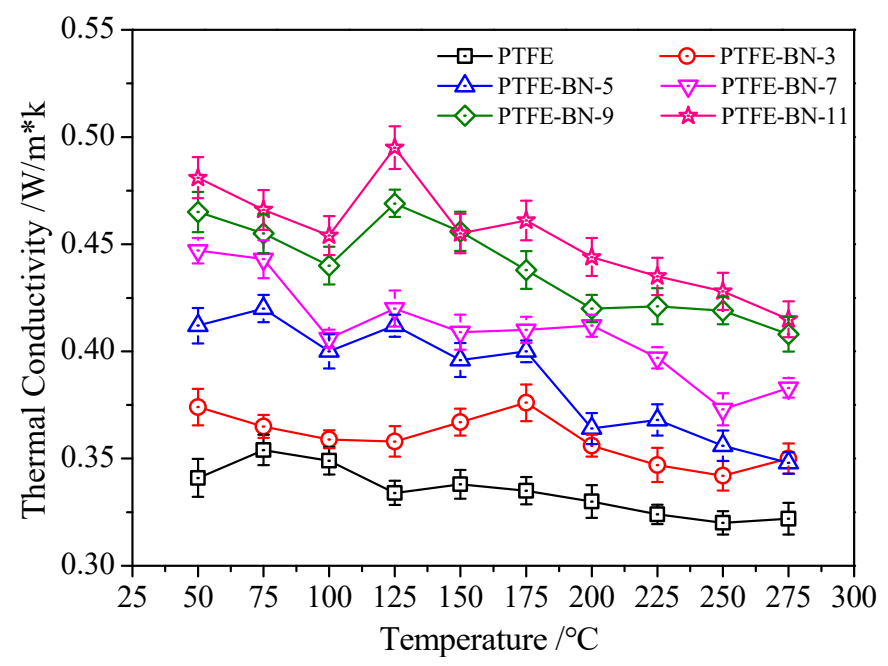

Figure 3. Thermal conductivity of specimens from 50 to $275^{\circ} \mathrm{C}$.

Figure 4 shows the thermal diffusivity of PTFE and PTFE/BN composites. It indicates that the thermal diffusivity of specimens increased with increased BN loading. For PTFE alone, the value of thermal diffusivity is $0.128 \mathrm{~mm}^{2} / \mathrm{s}$, while it reaches up to $0.185 \mathrm{~mm}^{2} / \mathrm{s}$ when the BN concentration is $11 \mathrm{wt} \%$; it improved by $44 \%$. Thermal diffusivity reflects the ability of an object to reach a uniform temperature. This means the higher thermal diffusivity, the more quickly heat transfers.

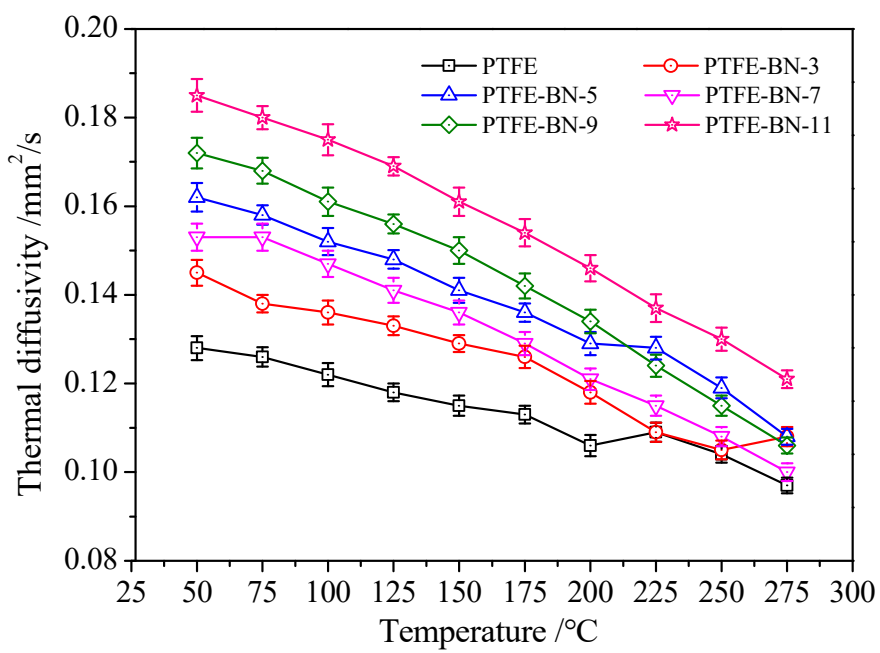

Figure 4. Thermal diffusivity of PTFE and PTFE/BN specimens. 
In recent years, h-BN was found to be structurally similar to graphite and shows equally excellent thermal transport performance [22]. In this study, h-BN with high thermal conductivity, as the inorganic filler, was added into PTFE to enhance the thermal transport performance. According to heat conduction theory, the thermal transport performance of polymer composites is mainly determined or influenced by the interaction role of the polymer matrix and the fillers [27]. In this study, the filled BN sheets were seen as the isolated heat conduction centers. These centers uniformly distributed in the PTFE matrix and formed different thermal paths. These paths were reticulated, chain-like, and interconnected with each other, forming a strong heat conduction network inside the material, and improving thermal conductivity $[28,29]$. Thus, the more the heat conduction centers, the more easily interconnected the heat conduction network constructed, and the higher the thermal conductivity. In this paper, the experimental results agree with the above analysis. That is, the thermal conductivity of PTFE/BN composites increased gradually with increased BN loading.

\subsection{Spectral Reflectance Properties}

The results of the spectral reflectance properties of PTFE and PTFE/BN specimens are shown in Figure 5. Firstly, it was found that the intensity differences in light reflection between the PTFE and the PTFE/BN composites are obviously different. For neat PTFE, the light reflectance is obviously lower than that of PTFE/BN composites when the wavelength is longer than $320 \mathrm{~nm}$ (including ultraviolet light, visible light, and infrared light), and it decreases quickly with increased wavelength. However, the light reflectance of PTFE/BN composites is quickly enhanced with increased wavelength when it is longer than $320 \mathrm{~nm}$, which is totally inversed compared with PTFE alone. Secondly, it was still observed that the light reflectance becomes gradually stronger with the increased BN loading in the area from 320 to $2500 \mathrm{~nm}$, although the differences are not very clear. When the wavelength is less than $320 \mathrm{~nm}$, it seems that the PTFE has the highest light reflectance, and that this decreases with BN loading. It is obvious that the high light reflectance of PTFE/BN composites was caused by the filled BN sheets. This may be due to the uniform dispersion of BN sheets in the PTFE matrix, and thus a small amount of BN filler loading could have greatly improved the light reflectance. However, the deeper causes require further study.

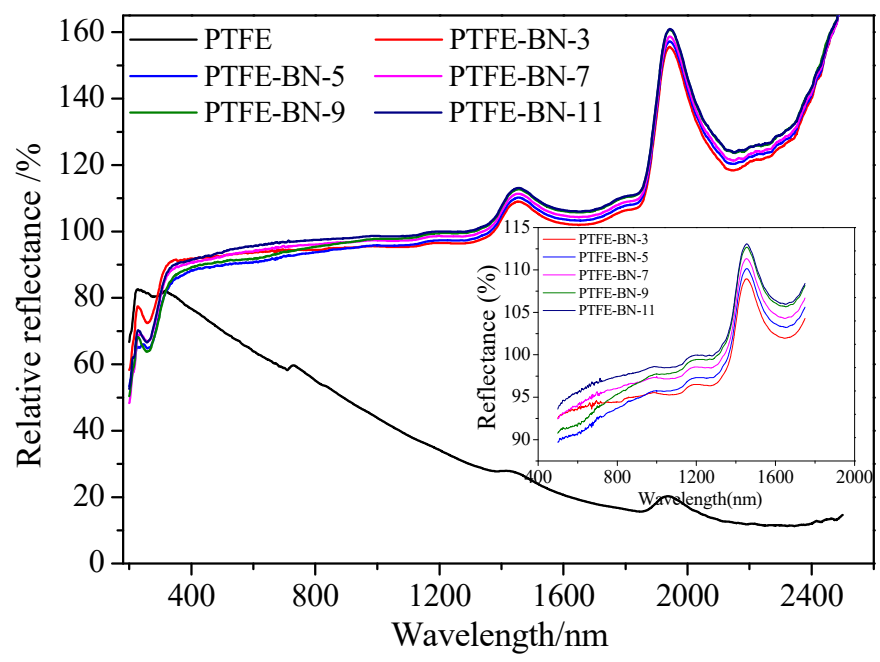

Figure 5. Spectral reflectance of PTFE and PTFE/BN specimens. 


\subsection{Surface Sediment Properties}

Figure 6 shows the surface morphologies of specimens before and after arc ablation. It was found that two different regions exist on the specimen surface (green line is the actual boundary between the arc ablation region and the non-ablation region). The left of the green line is the non-ablation region, while the right of the green line is the arc ablation region. In the arc ablation region, it was observed that some sediment deposited on the surface of the specimens (Figure $6 \mathrm{~b}-\mathrm{d}$ ). In addition, the amount of the sediment increased with increased BN loading. In the arc ablation process, the PTFE molecules decompose, firstly under the high temperature and the strong ultraviolet light of the arc; subsequently, the filled BN particles are left on the composites' surfaces. Therefore, it is understandable that the sediment was only observed on PTFE/BN composites, as well as the increased amount of the sediment with increased BN loading.
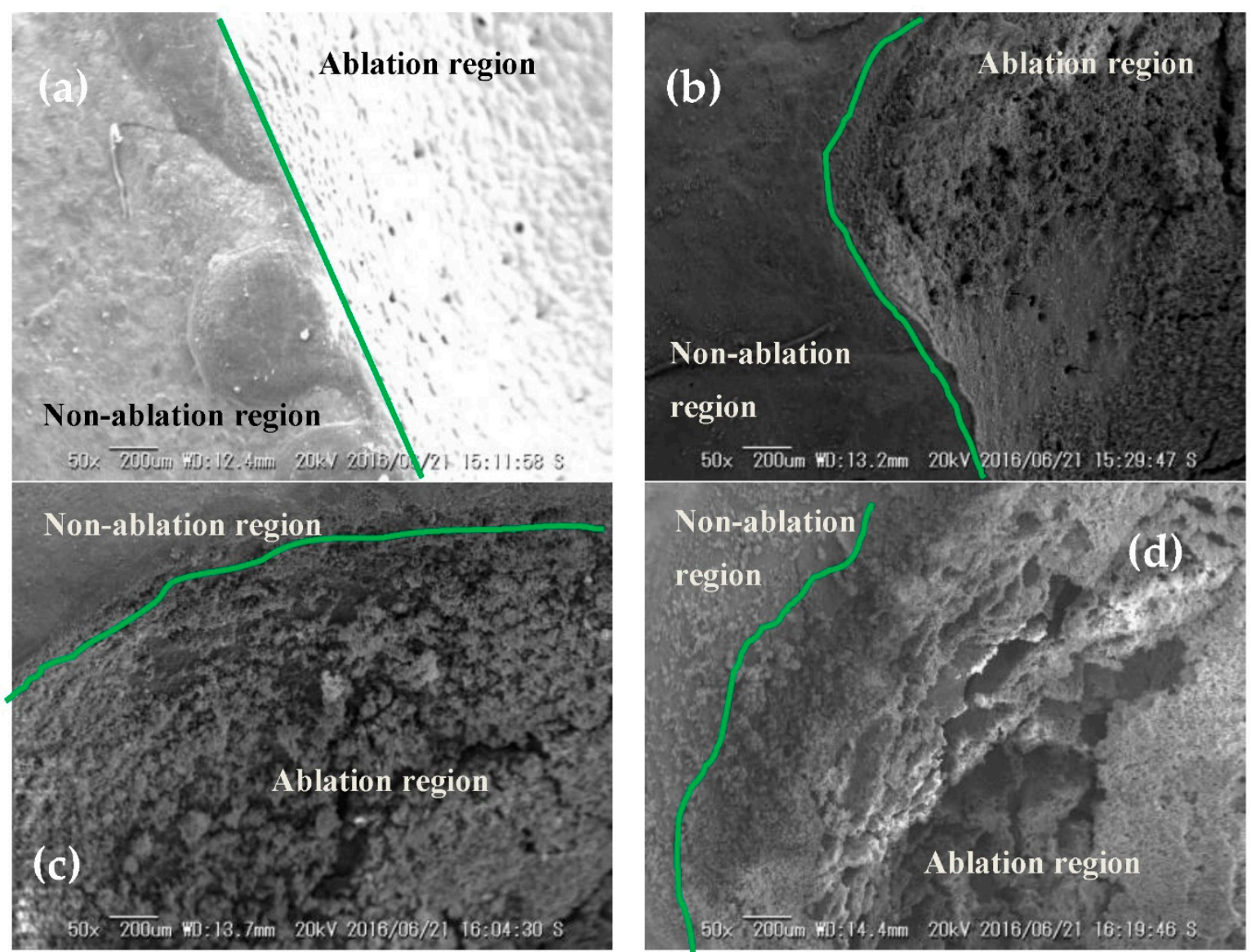

Figure 6. Surface morphology characteristics of specimens after arc ablation: (a) PTFE, (b) PTFE-BN-3, (c) PTFE-BN-7, and (d) PTFE-BN-11.

\subsection{Arc Ablation Properties}

The arc ablation resistance performance results are shown in Figure 7. These indicate that the amount of arc ablation decreases with increased BN loading, which means the arc ablation resistance performance improves considerably. For example, the arc ablation amounts were 22.7, 21.1, 16.2, 14.9, 2.77, and $2.65 \mathrm{mg}$, respectively, for neat PTFE and all of the PTFE/BN specimens, from low BN loading to high BN loading. The weight loss decreased by $88.5 \%$ for PTFE-BN-11 sample compared with that of unfilled PTFE. This obvious decline in ablation mass would be very helpful for nozzles to prolong their service life and improve the operation reliability of circuit breakers. 


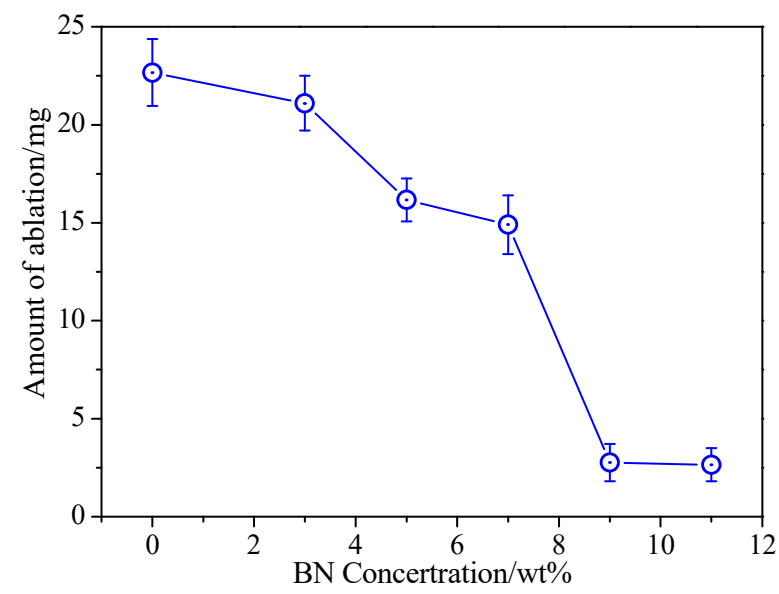

Figure 7. Arc ablation resistance of PTFE/BN composites with various BN loadings.

\subsection{AC Breakdown Performances}

Figure 8 shows the AC breakdown characteristics of PTFE/BN composites. The error bar and the solid column are standard deviation and the average breakdown strength of 10 samples, respectively. It shows that the $\mathrm{AC}$ breakdown strength $\left(E_{\mathrm{AC}}\right)$ of specimens increased monotonously with increasing $\mathrm{BN}$ filler loading when the filler loading was below $9 \mathrm{wt} \%$ ( $E_{\mathrm{AC}}$ is $40.3 \mathrm{kV} / \mathrm{mm}$ for PTFE-BN-9 specimen). With further increases in BN filler loading, the $E_{\mathrm{AC}}$ remained a stable value $\left(E_{\mathrm{AC}}\right.$ is $40.8 \mathrm{kV} / \mathrm{mm}$ for PTFE-BN-11 specimen). Compared with pure PTFE ( $E_{\mathrm{AC}}$ is $\left.31.16 \mathrm{kV} / \mathrm{mm}\right)$, the highest $E_{\mathrm{AC}}$ of PTFEBN-11 was enhanced by $30.93 \%$.

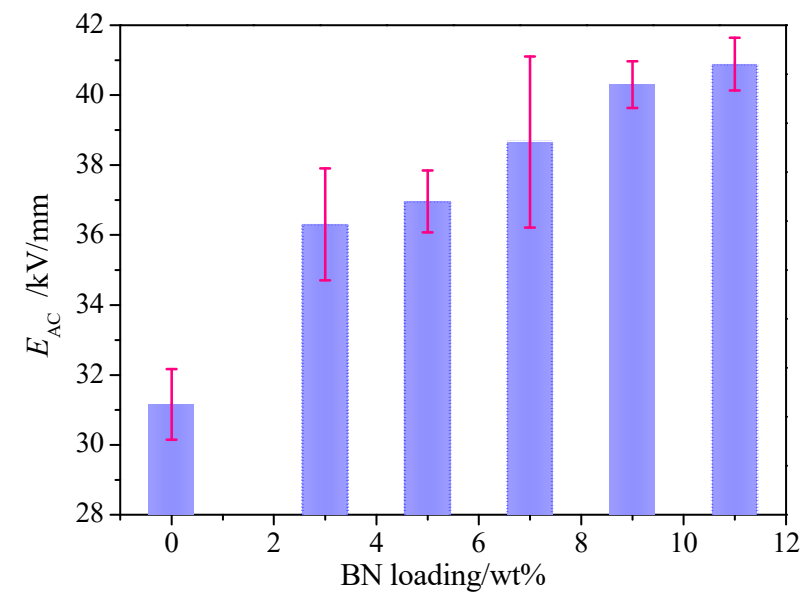

Figure 8. Influence of $\mathrm{BN}$ filler-content on $E_{\mathrm{AC}}$ of PTFE/BN composites.

\section{Discussion}

To investigate, in detail, the factors enhancing arc ablation resistance and AC dielectric breakdown performance, the influences of thermal conductivity on the arc ablation amount and $E_{A C}$ of specimens are shown in Figure 9. It seems that the amount of arc ablation decreases and breakdown strength increases with increases in thermal conductivity, which means that the higher the thermal conductivities, the more excellent the arc ablation resistances and breakdown performances. The above results indicate that the thermal transport property has obvious influences on the arc ablation and dielectric characteristics of nozzle materials. The detailed explanations are given as follows. 


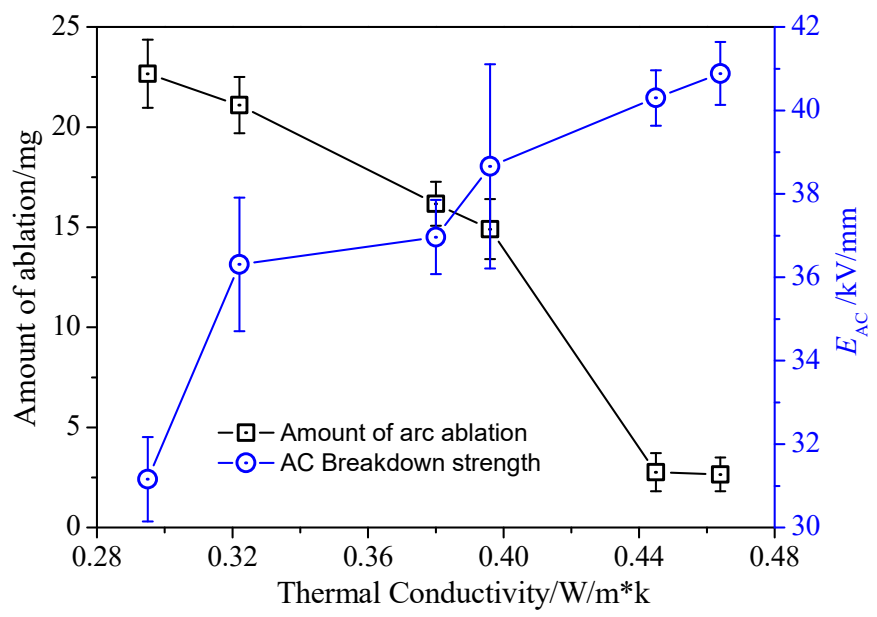

Figure 9. Correlation between thermal conductivity and the amount of arc ablation and breakdown performance.

An arc is a kind of plasma discharge, which is accompanied by the creation of high temperature and the emission of strong light. The research $[8,26,30]$ has indicated that the temperature of an arc can reach 20,000 K, based on measurements in a large current region above $1 \mathrm{kA}$. The lights created by arcs include infrared light, visible light, and ultraviolet light. Both the energy from high temperature and strong light radiation can decompose polymer composites, but the damage to materials differs from one another. When a high temperature of tens of thousands of degrees is continuously subjected to polymers, the polymer molecules decompose rapidly. Lights can also destroy polymeric materials in their own ways; the chemical bonds of molecular chains can be broken by ultraviolet light, and the polymers may become unstable if continuously exposed to infrared light. In this study, the light reflectance of PTFE/BN composites was considerably higher than that of PTFE when the wavelength was longer than $320 \mathrm{~nm}$. Moreover, it increased with increased BN loading. This means the effect of light on the PTFE breakdown was weakened and resulted in the improvement in arc ablation resistance.

During the arc ablation process, the heat from the arc accumulates on the specimen's surface, leading to the local temperature increases and rapid heat accumulation. Finally, when the accumulated heat reaches a certain temperature (heat-resisting limitation) within polymers, the materials decompose. Therefore, avoiding heat accumulation and making the heat transfer away as much as possible are very important. In this study, the improved thermal conductivity and thermal diffusivity of the PTFE/BN composites were critical to reduce the arc heat accumulation. The increased thermal conductivity means more heat energy could be transferred, while the increased thermal diffusivity means heat could be more quickly diffused into the surrounding medium. Thus, both the thermal conductivity and thermal diffusivity of the PTFE/BN composites increased, which resulted in a faster and greater amount of heat transport to the surrounding material, which then decreased excessive accumulation of heat in a local area during arc ablation. Finally, the performance of arc ablation resistance was improved.

In addition to the above causes, the surface sediment may have been another factor that improved the arc ablation performance of the PTFE/BN composites. It is mentioned in Section 3.4 that the surface sediments are the residual BN sheets after arc ablation. These $\mathrm{BN}$ sheets cover the surface of the ablation region and form a protective layer, which could prevent the subsequent ablation of inner PTFE material.

Thermal dielectric breakdown theory [31,32] can be used to explain the improvement in $E_{\mathrm{AC}}$. According to the thermal breakdown model, when the heat accumulation exceeds the heat dissipation by a certain value during voltage application, breakdown occurs. Thus, the reduction in heat accumulation is conducive to dielectric strength. Especially for the $\mathrm{AC}$ condition, this heat is created through dielectric loss during the voltage polarity, 
periodically. Our experiment results are consistent with the above analysis. It is obvious that AC breakdown strength increases with increasing thermal conductivity of specimens. Refs. $[20,33,34]$ reported a similar result to our study, which is that the addition of BN $(10 \mathrm{wt} \%)$ results in the enhancement in both thermal conductivity and breakdown strength.

\section{Conclusions}

In this study, PTFE/BN composites were prepared to investigate the effect of BN loading on arc ablation and breakdown performances, as well as the corresponding mechanisms. Finally, some conclusions were formed as follows:

The thermal conductivity and thermal diffusivity of PTFE/BN composites increased by $41 \%$ and $44 \%$, respectively, with increased BN loading compared with those of pure PTFE. The improvement in thermal conductivity was mainly attributed to the enhancement of thermal diffusivity. The light reflectance also obviously increased for PTFE/BN composites when the wavelength was longer than $320 \mathrm{~nm}$.

The arc ablation resistance performance of PTFE/BN composites was greatly improved with increased BN loading. It was improved by $88.5 \%$ for PTFE-BN-11 specimens when compared with pure PTFE. These excellent performances can be attributed to the increases in thermal conductivity, thermal diffusivity, and light reflectance, and the resistance role of surface sediment created during the arc ablation process.

Author Contributions: Author Contributions: X.Z., Y.N. and S.L. conceived the presented idea; B.S., T.Z. and S.Y. prepared the specimens, Y.N., K.W., T.Z. and S.Y. measured the data; X.Z., Y.N., X.Z. and S.L. analyzed the experimental data; and X.Z. and Y.N. primarily wrote the manuscrpit. All authors have read and agreed to the published version of the manuscript.

Funding: This work is supported by the Basic Research Plan of Yunnan Province-Youth Project (202001AU070062), and the Development Program of Shaanxi Province (grant number 2018DCXLGY-07-04).

Institutional Review Board Statement: Not applicable.

Informed Consent Statement: Not applicable.

Conflicts of Interest: The authors declare no conflict of interest.

\section{References}

1. Huang, D.; Shu, Y.; Ruan, J.; Hu, Y. Ultra High Voltage Transmission in China: Developments, Current Status and Future Prospects. Proc. IEEE 2009, 97, 555-583. (In Chinese) [CrossRef]

2. Verma, A.R.; Reddy, B.S. Evaluation of ceramic insulators for UHVDC transmission. IEEE Trans. Dielectr. Electr. Insul. 2018, 25, 38-45. [CrossRef]

3. Wang, Z.; Yu, Q.; Mou, Y.; Ji, Y.; Hu, J.; Chen, S.; He, J. Analysis and mitigation of low-frequency resonance in a long-distance UHVDC \pm 1100 kV system. Electr. Power Syst. Res. 2018, 162, 118-124. [CrossRef]

4. Shu, Y.; Zhang, W. Research of Key Technologies for UHV Transmission. Proc. CSEE 2007, 27, 1-6. (In Chinese)

5. Li, Y.; Zhao, M.; Zhou, Q.; Geng, B. Research on Arc Ablation Resistance of PTFE Improved by Introducing Inorganic Filler. In Proceedings of the 2008 International Symposium on Electrical Insulating Materials, Yokkaichi, Japan, 7-11 September 2008; pp. 7-11.

6. Zhang, J.L.; Yan, J.D.; Murphy, A.; Hall, W.; Fang, M.T.C. Computational investigation of arc behavior in an auto-expansion circuit breaker contaminated by ablated nozzle vapor. IEEE Trans. Plasma Sci. 2002, 30, 706-719. [CrossRef]

7. Yan, J.; Fang, T.; Liu, Q. Dielectric breakdown of a residual SF/sub 6/ plasma at $3000 \mathrm{~K}$ under diatomic equilibrium. IEEE Trans. Dielect. Elect. 1997, 4, 114-119. [CrossRef]

8. Sato, M.; Horinouchi, K.; Hiza, S.; Nakamura, Y. Ablated mass of PTFE nozzle due to high-current SF6 arc exposure: Formulation of ablated mass. Electr. Eng. Japan. 2019, 208, 29-38.

9. Petchanka, A.; Reichert, F.; Gonzalez, J.-J.; Freton, P. Modelling of the deformation of PTFE-nozzles in a high voltage circuit breaker due to multiple interruptions. J. Phys. D Appl. Phys. 2016, 49, 135201. [CrossRef]

10. Seeger, M.; Tepper, J.; Christen, T.; Abrahamson, J. Experimental study on PTFE ablation in high voltage circuit-breakers. J. Phys. D Appl. Phys. 2006, 39, 5016-5024. [CrossRef]

11. He, J.; Wang, K.; Li, J. Application of an Improved Mayr-Type Arc Model in Pyro-Breakers Utilized in Superconducting Fusion Facilities. Energies 2021, 14, 4383. [CrossRef] 
12. Eichhoff, D.; Kurz, A.; Kozakov, R.; Gött, G.; Uhrlandt, D.; Schnettler, A. Study of an ablation-dominated arc in a model circuit breaker. J. Phys. D Appl. Phys. 2012, 45, 305204. [CrossRef]

13. Wang, C.; Ding, H.; Wang, H. Thermodynamic Model and Dynamic Temperature Compensation in Positive-Pressure-Based Sonic Nozzle Gas Flow Standard. IEEE Trans. Instrum. Meas. 2013, 62, 1154-1165. [CrossRef]

14. Reichert, F.; Gonzalez, J.-J.; Freton, P. Modelling and simulation of radiative energy transfer in high-voltage circuit breakers. J. Phys. D Appl. Phys. 2012, 45, 375201. [CrossRef]

15. Pawar, S.; Sharma, A. Multiphysics Simulation of Welding-Arc and Nozzle-Arc System: Mathematical-Model, Solu-tionMethodology and Validation. J. Inst. Eng. (India) Ser. C 2019, 100, 145-152. [CrossRef]

16. Nie, Y.; Yang, L.; Han, Y.; Li, S. Effect of BN size on arc ablation characteristics of PTFE material. In Proceedings of the International Conference on Condition Monitoring and Diagnosis (CMD), Xi'an, China, 25-28 September 2016; pp. 499-502.

17. Nie, Y.; Yang, L.; Han, Y.; Li, S. Effect of BN size on AC breakdown performances of PTFE/BN composites. In Proceedings of the International Conference on Electrical Materials and Power Equipment (ICEMPE), Xi'an, China, 14-17 May 2017 ; pp. 635-638.

18. Kowalski, L.; Duszczyk, J.; Katgerman, L. Thermal conductivity of metal powder-polymer feedstock for powder injection moulding. J. Mater. Sci. 1999, 34, 1-5. [CrossRef]

19. El-Broloss, T.; Ibrahim, S. Photoacoustic measurement of thermal properties of polystyrene metal oxide composites. Thermochim. Acta 2010, 509, 46-49. [CrossRef]

20. Yang, H.; Chen, Q.; Chi, H.; Zhang, J.; Wang, X. Dielectric and Thermal Conductivity Characteristics of Epoxy Res-in-Impregnated H-BN/CNF-Modified Insulating Paper. Polymers 2020, 12, 2080. [CrossRef]

21. Yung, K.C.; Liem, H.; Choy, H.S. Prerequisite for maximizing thermal conductivity of epoxy laminate using filler. J. Mater. Sci. Mater. Electron. 2012, 24, 1095-1104. [CrossRef]

22. Song, W.-L.; Wang, P.; Cao, L.; Anderson, A.; Meziani, M.J.; Farr, A.J.; Sun, Y.-P. Polymer/Boron Nitride Nanocomposite Materials for Superior Thermal Transport Performance. Angew. Chem. Int. Ed. 2012, 51, 6498-6501. [CrossRef]

23. Cheng, W.-C.; Hsieh, Y.-T.; Liu, W.-R. Enhanced Thermal Conductivity of Silicone Composites Filled with Few-Layered Hexagonal Boron Nitride. Polymers 2020, 12, 2072. [CrossRef]

24. Raza, M.A.; Westwood, A.; Brown, A.; Stirling, C. Performance of graphite nanoplatelet/silicone composites as thermal interface adhesives. J. Mater. Sci. Mater. Electron. 2012, 23, 1855-1863. [CrossRef]

25. Li, W.; Feng, W.; Huang, H. High-performance epoxy resin/silica coated flake graphite composites for thermal conductivity and electrical insulation. J. Mater. Sci. Mater. Electron. 2016, 27, 6364-6370. [CrossRef]

26. Wilbers, A.; Kroesen, G.; Timmermans, C.; Schram, D. The continuum emission of an arc plasma. J. Quant. Spectrosc. Radiat. Transf. 1991, 45, 1-10. [CrossRef]

27. Swartz, E.; Pohl, R. Thermal Boundary Resistance. Rev. Mod. Phys. 1989, 61, 605-668. [CrossRef]

28. Zhou, W.; Yu, D.; Wang, C.; An, Q.; Qi, S. Effect of filler size distribution on the mechanical and physical properties of aluminafilled silicone rubber. Polym. Eng. Sci. 2008, 48, 1381-1388. [CrossRef]

29. Qiu, Y.; Liang, J. Thermal conductivity of $\mathrm{PP} / \mathrm{Al}(\mathrm{OH})_{3} / \mathrm{Mg}(\mathrm{OH})_{2}$ composites. Compos. Part B Eng. 2013, 44, $248-252$.

30. Oomori, T.; Hamano, S.; Sasao, H.; Ueda, Y. Optical Observation of Self-Gas-Flow in GCB. IEEE. Trans. Power. Appar. Syst. 1983, 3, 1408-1413.

31. Moon, P.H. The Theory of Thermal Breakdown of Solid Dielectrics. Trans. Am. Inst. Electr. Eng. 1931, 50, 1008-1021. [CrossRef]

32. Ieda, M. Dielectric Breakdown Process of Polymers. IEEE Trans. Electr. Insul. 1980, EI-15, 206-224. [CrossRef]

33. Donnay, M.; Tzavalas, S.; Logakis, E. Boron nitride filled epoxy with improved thermal conductivity and dielectric breakdown strength. Compos. Sci. Technol. 2015, 110, 152-158. [CrossRef]

34. Huang, L.; Lv, X.; Tang, Y.; Ge, G.; Zhang, P.; Li, Y. Effect of Alumina Nanowires on the Thermal Conductivity and Electrical Performance of Epoxy Composites. Polymers 2020, 12, 2126. [CrossRef] [PubMed] 